\title{
Formação de professores para a construção de Jogos Educacionais Digitais: uma revisão sistemática da literatura
}

\author{
Teacher training for the construction of Digital Educational Games: a systematic literature review \\ Formación de profesores para la construcción de Juegos Educativos Digitales: una revisión
}

sistemática de la literatura

Recebido: 08/10/2021 | Revisado: 15/10/2021 | Aceito: 18/10/2021 | Publicado: 20/10/2021

Thiago Moura Barbosa

ORCID: https://orcid.org/0000-0002-0047-5394 Universidade Federal do Rio Grande do Norte, Brasil E-mail: thiagoobarbossa@gmail.com

Akynara Aglaé Rodrigues Santos da Silva Burlamaqui

ORCID: https://orcid.org/0000-0002-8941-9128

Universidade Federal Rural do Semi-Árido, Brasil E-mail: akynara@gmail.com

Aquiles Medeiros Filgueira Burlamaqui

ORCID: https://orcid.org/0000-0001-6754-8335

Universidade Federal do Rio Grande do Norte, Brasil E-mail: aquilesburlamaqui@gmail.com

\begin{abstract}
Resumo
Considerando as mudanças ocorridas na escola ao longo dos anos, causadas pela inserção das tecnologias digitais no contexto educacional, passou-se a exigir cada vez mais de nossos professores, novas habilidades e novas competências para se trabalhar com atuais aprendizes do século XXI. Em meio a todas essas tecnologias que podemos encontrar cada dia mais presentes na escola, uma que vem se destacando no contexto da educação é a dos jogos digitais, principalmente os que são produzidos com finalidades educacionais. No entanto, na medida em que os jogos digitais se mostram como uma nova proposta para que os professores possam trabalhar com os estudantes, surge o questionamento em relação à oferta de formação docente que vise preparar esses professores não apenas para o uso, mas também para a construção desses novos recursos educacionais digitais, uma vez que são estes os profissionais que conhecem os conteúdos e as práticas pedagógicas, assim como a realidade da escola e dos estudantes. Em vista disso, objetiva-se a partir deste trabalho apresentar uma Revisão Sistemática da Literatura que buscou investigar a existência de trabalhos científicos, publicados entre janeiro de 2015 a abril de 2021, acerca da oferta de formação destinada a professores para a construção de jogos educacionais digitais. Para a construção da revisão, foram adotadas as etapas de planejamento, condução e relatório apresentadas na metodologia do artigo. Dessa forma, destaca-se que os estudos encontrados ao longo da revisão foram criteriosamente analisados e os resultados encontrados foram sintetizados ao longo deste trabalho.
\end{abstract}

Palavras-chave: Formação de professores; Jogos educacionais digitais; RSL.

\begin{abstract}
Considering the changes that have occurred in the school over the years, caused by the insertion of digital technologies in the educational context, our teachers have increasingly demanded new skills and competences to work with current 21 st century learners. Among all the technologies that we can find each day even more present in the school environment, one that has been standing out in the context of education is the use of digital games, especially those produced for educational purposes. However, as digital games show themselves as a new proposal for teachers to work with students, the question arises regarding the offer of a specific teacher training that aims to prepare these teachers not only for use as also for the construction of these new digital educational resources, considering that these are the professionals who know the pedagogical contents and practices, as well as the reality of the school and students. Therefore, this work seeks to present a Systematic Literature Review that sought to investigate the existence of scientific papers, published between January 2015 and April 2021, about the provision of training for educators for the construction of digital educational games. For the construction of the review, we adopted the steps of planning, conducting and reporting presented in the article's methodology. Thus, it is emphasized that the studies found throughout the review were carefully analyzed and the results found were synthesized throughout this work.
\end{abstract}

Keywords: Teacher training; Digital educational games; SLR. 


\begin{abstract}
Resumen
Considerando los cambios ocurridos en la escuela con los años, causadas por la inserción de las tecnologías digitales en el contexto educacional, pasó a exigir cada vez más de nuestros profesores, nuevas habilidades y nuevas competencias para trabajar con actuales aprendices del siglo XXI. En medio a todas esas tecnologías que podemos encontrar cada día más presentes en la escuela, una que viene sobresaliendo en el contexto educacional es la de los juegos digitales, principalmente los que son producidos con finalidades educacionales. Sin embargo, a medida que los juegos digitales se muestran como una nueva propuesta para que los profesores puedan trabajar con los estudiantes, surge el cuestionamiento en relación a la oferta de formación docente que pretenda preparar estos profesores no apenas para el uso, pero también para la construcción de esos nuevos recursos educacionales digitales, una vez que son estos los profesionales que conocen los contenidos y las prácticas pedagógicas, así como la realidad de la escuela y de los estudiantes. En vista de eso, el objetivo a partir de esto trabajo es presentar una Revisión Sistemática de la Literatura que buscó investigar la existencia de trabajos científicos, publicados desde enero de 2015 hasta abril de 2021, acerca de la oferta de formación destinada a profesores para la construcción de juegos educacionales digitales. Para la construcción de la revisión, fueron adoptados los pasos de planificación, manejo e informe presentadas en la metodología del artículo. De esa manera, se sobresale que los estudios encontrados a lo largo de la revisión fueron detenidamente analizados y los resultados encontrados fueron sintetizados a lo largo de este trabajo.
\end{abstract}

Palabras clave: Formación de profesores; Juegos educativos digitales; RSL.

\title{
1. Introdução
}

É possível notar, com o passar do tempo, que a escola que um dia frequentamos já não é mais a mesma. Isso acontece porque os sistemas educacionais em todo o mundo têm passado por constantes mudanças, na tentativa de melhor atender e suprir as necessidades educacionais dos atuais aprendizes do século XXI, verdadeiros nativos digitais, que já nasceram rodeados por tecnologias digitais diversas e que o sistema educacional tradicional do século passado já não dá mais conta de ensinar (Prensky, 2001).

Paralelamente a isso, passou-se a exigir cada vez mais de nossos educadores novas habilidades e novas competências ao ensinar, capazes de acompanhar as profundas mudanças acarretadas pela inserção das Tecnologias Digitais de Informação e Comunicação (TDIC) nas escolas. Atrelado a essas exigências, passou-se a questionar também a necessidade de formação docente adequada, capaz de preparar os professores para atuar na escola com e por meio dessas tecnologias (Kenski, 2013).

No Brasil, diversas políticas e iniciativas governamentais como o Programa Nacional de Informática Educativa (PRONINFE), o Programa Nacional de Tecnologia Educacional (ProInfo) e mais recente a Política de Inovação Educação Conectada (PIEC), foram lançadas ao longo dos anos na tentativa de não apenas disseminar tecnologias nas escolas, mas também capacitar os professores para o uso pedagógico das TDIC dentro e fora da sala de aula (Brasil, 1994, 2007, 2021).

Infelizmente, algumas dessas inciativas apresentaram resultados pouco significativos em relação ao uso pedagógico, crítico e reflexivo a respeito das TDIC, limitando-se, muitas vezes, apenas ao uso técnico e sem objetivo pedagógico definido para serem aplicadas em sala de aula.

Em meio a todos esses desafios, algumas dessas tecnologias e recursos digitais têm chegado aos poucos até as escolas de todo o país. Entre estas, uma que tem e destacado é a dos jogos digitais, principalmente os que são construídos para serem utilizados com finalidades educacionais.

No tocante a estes, Amélio (2018) destaca que dentre as indústrias relacionadas à criatividade e a cultura, o mercado relativo aos jogos digitais tem apresentado um crescimento significativo, tanto financeiramente como em perspectivas de desenvolvimento.

Uma prova disso, são os dados divulgados pelo II Censo da Indústria Brasileira de Jogos Digitais, realizado pelo Ministério da Cultura (MinC) em parceria com a Organização das Nações Unidas para a Educação, a Ciência e a Cultura (Unesco) no ano de 2018, que revelam um aumento de $146 \%$ no número de entidades desenvolvedoras de jogos digitais, entre os anos de 2014 a 2018 no país (Brasil, 2018).

Os dados também revelam, que nos últimos dois anos que antecederam 2018, foram produzidos 1.718 jogos no Brasil, 
dentre estes 874 dizem respeito a jogos de aprendizagem e 785 correspondem a jogos digitais voltados ao entretenimento (Brasil, 2018).

Em relação a estes tipos de jogos, uma das principais diferenças entre eles está relacionada ao fato de que os jogos de entretenimento são construídos com foco principal no lúdico, onde a principal expectativa em relação a eles é a diversão, enquanto os jogos de aprendizagem são desenvolvidos com o intuito de ajudar quem os joga a desenvolver novas habilidades e adquirir novos conhecimentos ou para fortalecer os conhecimentos já adquiridos, ideal para serem aplicados no contexto educacional (Boller \& Kapp, 2018).

Essa tendência em relação ao uso de jogos digitais no campo da educação, já vem sendo apontada ao longo de mais de uma década por meio de relatórios anuais publicados pelo projeto Horizon Report, criado pela entidade norte-americana sem fins lucrativos EDUCAUSE para mapear possíveis tendências e tecnologias emergentes que podem impactar no futuro, incluindo o da educação (Educause, 2021).

Ainda nesse sentido, diversos autores como Mattar (2010), Prensky (2010, 2012), McGonigal (2012), Petry (2016) e Meira e Blikstein (2020), têm apontado em suas diversas obras, evidências, possibilidades e metodologias para a inserção e uso de jogos digitais na escola.

Diante de todos esses indicativos, é possível afirmar que a cada dia estão sendo construídos novos jogos educacionais digitais e que há espaço na escola para inserir, pensar e utilizar esse recurso no ambiente da sala de aula, apresentando-se como uma nova proposta para que os professores, principalmente os da educação básica, possam trabalhar os conteúdos curriculares com os estudantes por meio destes.

No entanto, é sempre bom ressaltar que não basta inserir estes novos recursos digitais educacionais no ambiente escolar. É preciso dar condições e subsídios aos profissionais docentes, para a utilização e principalmente para a construção ou participação na criação dessas novas tecnologias, uma vez que são estes os profissionais que conhecem os conteúdos curriculares, as práticas pedagógicas e a realidade da escola e dos estudantes.

Em vista disso, no que se refere aos jogos educacionais digitais, torna-se possível nos fazermos o seguinte questionamento: estariam os professores da educação básica do país, sendo preparados para a construção desse tipo de recurso educacional digital?

Dessa forma, destaca-se a necessidade de que sejam realizadas verificações do estado de conhecimento a respeito da oferta de formação destinada ao público docente para a construção de jogos digitais com finalidades educacionais.

Nesse sentido, este trabalho apresenta os resultados de uma Revisão Sistemática da Literatura (RSL), que possuiu como objetivo investigar trabalhos científicos acerca da oferta de formação destinada à professores para a construção de Jogos Educacionais Digitais (JED).

A motivação para a realização da RSL, se deu em função de um trabalho de dissertação ainda em processo de construção, no âmbito do Programa de Pós-graduação em Inovação em Tecnologias Educacionais (PPgITE) da Universidade Federal do Rio Grande do Norte (UFRN). Dessa maneira, será realizado um recorte dos dados e informações apresentados de forma inédita neste artigo, para a construção de um capítulo de revisão sistemática dentro da dissertação em construção.

Contudo, este trabalho encontra-se organizado em 10 seções, de forma que na Seção 1, são apresentados alguns pontos iniciais a partir da introdução. Na Seção 2, são apresentados alguns conceitos relacionados aos jogos educacionais digitais e como estes podem ser aplicados no processo de ensino-aprendizagem. Na Seção 3, é mostrada e detalhada a metodologia que foi utilizada na construção da revisão sistemática da literatura. Na Seção 4, são apresentados os resultados das etapas seguidas para a construção da RSL. Já na Seção 5, são apresentadas algumas respostas às questões de pesquisa. Na Seção 6, são exibidos alguns breves resumos sobre as experiências de formação encontradas nos trabalhos analisados, assim como uma comparação e discussão entre os trabalhos finais selecionados pela revisão. Na Seção 7, são descritas as principais 
possíveis ameaças à validade do trabalho. Na Seção 8, são expostas as considerações finais do trabalho. Na Seção 9, são realizados os agradecimentos a todos que contribuíram direta e indiretamente para a construção deste trabalho e por fim, na Seção 10 são mostradas as referências utilizadas na construção deste artigo.

\section{Os Jogos Educacionais Digitais e as Possibilidades de Uso}

Os jogos educacionais, também conhecidos como jogos sérios (serious games) ou jogos instrucionais, são jogos construídos com propósitos que vão além do simples entretenimento, onde, a maior finalidade destes é a sua utilização de forma educacional e estratégica. Em sua maioria, esse gênero de jogo busca possibilitar a quem joga, um aprendizado significativo em relação à algum conteúdo ou temática abordada nos diversos níveis de ensino (Tavares, 2021; Boller \& Kapp, 2018).

Nos dias atuais tem se tornado cada vez mais comum a presença e utilização desse tipo de jogo, principalmente os digitais, em ambientes educacionais, como uma possibilidade pedagógica capaz de motivar e engajar a aprendizagem, onde estes são inseridos em planejamentos e práticas pedagógicas de muitos professores, que acabam utilizando-os como uma forma de suporte ao aprendizado dos estudantes (Tavares, 2021).

Todavia, apesar de evidenciarmos essa grande presença dos jogos no âmbito educacional, Mattar (2010) aponta que essa presença e utilização dos jogos na educação não é algo novo, segundo ele, isso ocorre muito antes até mesmo do surgimento dos primeiros videogames, quando se usava, por exemplo, os jogos de tabuleiro tradicionais como ferramentas para ensinar e aprender.

Em relação ao uso pedagógico dos jogos digitais, por parte dos estudantes e professores, Prensky (2010) e Mattar (2010) elencam diversas possibilidades e caminhos neste sentido, dentre as muitas possibilidades apontadas por eles, algumas que podemos destacar são:

- a integração dos jogos no contexto escolar, por meio de planos de ensino, planejamentos, atividades, entre outros;

- a utilização dos jogos e suas temáticas como referência para a realização de discussões em sala de aula;

- o uso de características e elementos encontrados nos jogos em atividades desenvolvidas com os estudantes; e

- a construção de jogos, por parte dos estudantes e/ou professores, como uma atividade educativa.

A partir de todos esses pontos expostos, podemos determinar que é possível ensinar e aprender por meio do uso de jogos educacionais digitais e que são diversas as possibilidades de integração e uso no contexto da educação, cabendo aos professores a tarefa de definir e encontrar a melhor estratégia para se trabalhar com os alunos por meio deste recurso educacional.

Contudo, é preciso destacar que antes de considerar inserir e utilizar jogos na sala de aula, é necessário que se tenham um bom planejamento prévio em relação a isso, com objetivos claros e bem definidos para se trabalhar competências e habilidades com os estudantes.

Por fim, destaca-se ainda que tão importante quanto a presença e uso dos jogos educacionais digitais na escola, é importante também a concepção, desenvolvimento e oferta de políticas públicas que visem garantir aos professores formação pedagógica tanto para o uso, como para a construção desses recursos digitais, uma vez que são eles os profissionais que conhecem os conteúdos, as práticas pedagógicas e a realidade dos estudantes e também da escola. 


\section{Metodologia}

Este trabalho mostra resultados de uma revisão sistemática da literatura, que buscou analisar estudos primários que apresentam uma discussão teórica ou experiência prática envolvendo a oferta de formação destinada a docentes e que possuíam como temática a construção de JED, no período de janeiro de 2015 a abril 2021.

Para Kitchenham e Charters (2007), uma RSL pode ser definida como uma maneira de identificar, avaliar e interpretar estudos disponíveis e considerados relevantes, capazes de trazer respostas a uma questão de pesquisa específica, um campo de conhecimento ou um fenômeno de interesse para pesquisa.

A metodologia utilizada nesta RSL, envolveu as etapas de Planejamento, Condução e Relatório seguindo o protocolo proposto por Kitchenham e Charters (2007).

É importante deixar claro que as informações descritas a partir deste ponto da seção, foram definidas ainda na etapa de planejamento da construção da revisão. A partir do planejamento realizado foram definidos: as bases de busca utilizadas na revisão; a String de busca utilizada na coleta dos estudos; as questões de pesquisa (QP); os critérios de inclusão (CI) e critérios de exclusão (CE); as etapas de análise dos trabalhos; os critérios de qualidade (CQ) e a escala utilizada na avaliação dos critérios.

As bases de dados utilizadas na busca de estudos primários foram as seguintes: ACM Digital Library, Google Scholar (até a página 10 da base, com o limite de 10 trabalhos por página), Portal de Periódicos CAPES, Red Iberoamericana de Innovación y Conocimiento Científico (REDIB) e Scopus.

A String de busca utilizada na pesquisa foi construída a partir de testes realizados no Google Scholar com palavraschave comumente encontradas na literatura. O objetivo de tais testes foi o de construir uma String de busca que pudesse retornar um número adequado de estudos, sem que a String se tornasse limitada ao ponto de reduzir o número trabalhos encontrados ou ampliada ao ponto de que o elevado número de trabalhos impedisse a análise destes.

Desta forma, a String construída e utilizada na pesquisa é a apresentada no Quadro 1.

Quadro 1 - String de busca utilizada.

\begin{tabular}{|c|}
\hline String de Busca \\
\hline ("jogos digitais" AND ("curso" OR "formação" OR "capacitação") AND ("professores" OR \\
"educadores"))
\end{tabular}

Fonte: Dados da pesquisa (2021).

No caso da String de busca mostrada no Quadro 1, os operadores lógicos "AND" e "OR" foram utilizados como forma de filtrar, nas bases pesquisadas, trabalhos que continham em seu texto os termos "jogos digitais" E "curso" OU “formação" OU “capacitação” E “professores” OU “educadores”.

Como toda revisão sistemática de literatura, especificar as questões de pesquisa que norteiam e buscam trazer respostas ao estudo é uma das partes mais importantes. Nesse sentido, como forma de auxiliar na condução desta RSL, foram formuladas e utilizadas as questões de pesquisa descritas no Quadro 2. 
Quadro 2 - Questões de pesquisa.

\begin{tabular}{|c|l|}
\hline Questão & \multicolumn{1}{|c|}{ Descrição } \\
\hline QP1 & $\begin{array}{l}\text { Existe a oferta de formação destinada a professores para a construção de jogos } \\
\text { educacionais digitais? }\end{array}$ \\
\hline QP2 & $\begin{array}{l}\text { Qual o perfil de quem ministra/oferta formação a professores para a construção de jogos } \\
\text { educacionais digitais? }\end{array}$ \\
\hline QP3 & $\begin{array}{l}\text { Como é realizada a oferta de formação destinada a professores para a construção de jogos } \\
\text { educacionais digitais? }\end{array}$ \\
\hline QP4 & $\begin{array}{l}\text { Que desafios podem ocorrer na oferta de formação destinada a professores para a } \\
\text { construção de jogos educacionais digitais? }\end{array}$ \\
\hline
\end{tabular}

Fonte: Dados da pesquisa (2021).

Como forma de filtrar os trabalhos mais relevantes a respeito do tema pesquisado e, também, para definir se estes poderiam ser aceitos ou rejeitados nesta revisão, as análises dos estudos encontrados foram feitas considerando os critérios de inclusão e critérios de exclusão formulados e apresentados nos Quadros 3 e 4, respectivamente.

Quadro 3 - Critérios de inclusão.

\begin{tabular}{|c|l|}
\hline $\begin{array}{c}\text { Critério de } \\
\text { Inclusão }\end{array}$ & \multicolumn{1}{c|}{ Descrição } \\
\hline CI1 & $\begin{array}{l}\text { Estudos primários que apresentam uma discussão teórica ou experiência prática } \\
\text { envolvendo a oferta de formação destinada a professores para a construção de jogos } \\
\text { educacionais digitais. }\end{array}$ \\
\hline CI2 & Estudos disponíveis em Português, Inglês e Espanhol. \\
\hline
\end{tabular}

Fonte: Dados da pesquisa (2021).

Quadro 4 - Critérios de exclusão.

\begin{tabular}{|c|l|}
\hline $\begin{array}{c}\text { Critério de } \\
\text { Exclusão }\end{array}$ & \multicolumn{1}{c|}{ Descrição } \\
\hline CE1 & $\begin{array}{l}\text { Estudos primários que não tratam sobre formação destinada a professores para } \\
\text { construção de jogos educacionais digitais. }\end{array}$ \\
\hline CE2 & Estudos redundantes (utilizada a versão mais recente do trabalho). \\
\hline CE3 & Estudos secundários e terciários. \\
\hline CE4 & Estudos que possuem menos de 05 páginas. \\
\hline CE5 & Estudos publicados antes do ano de 2015. \\
\hline CE6 & Tutoriais, capítulos de livros, relatórios técnicos, dados de censo etc. \\
\hline
\end{tabular}

Fonte: Dados da pesquisa (2021).

Após a seleção de estudos, realizada por meio da aplicação dos critérios de inclusão e exclusão, os artigos selecionados foram ainda analisados considerando três diferentes etapas, conforme mostrado no Quadro 5. 
Quadro 5 - Etapas de análise dos trabalhos.

\begin{tabular}{|c|l|}
\hline Etapas & \multicolumn{1}{|c|}{ Descrição } \\
\hline ETAPA 1 & Leitura do título, resumo e palavras-chave dos trabalhos encontrados. \\
\hline ETAPA 2 & Leitura da introdução e conclusão dos trabalhos que foram selecionados na ETAPA 1. \\
\hline ETAPA 3 & Leitura completa dos trabalhos selecionados na ETAPA 2. \\
\hline
\end{tabular}

Fonte: Dados da pesquisa (2021).

Cada uma das três etapas de análise serviu para filtrar e selecionar os trabalhos mais relevantes que se encaixavam com a temática e objetivo da RSL.

Como forma de extrair ainda mais informações a respeito dos trabalhos e, também, para tentar medir a "qualidade" destes, após a realização da análise especificada no Quadro 5, foram aplicados aos estudos finais selecionados os critérios de qualidade definidos e especificados no Quadro 6.

Quadro 6 - Critérios de qualidade.

\begin{tabular}{|c|l|}
\hline $\begin{array}{c}\text { Critério de } \\
\text { Qualidade }\end{array}$ & \multicolumn{1}{c|}{ Descrição } \\
\hline CQ1 & O trabalho apresenta uma definição clara dos objetivos da pesquisa? \\
\hline CQ2 & $\begin{array}{l}\text { O trabalho trata sobre a oferta de formação destinada a professores para a construção de } \\
\text { jogos educacionais digitais? }\end{array}$ \\
\hline CQ3 & $\begin{array}{l}\text { O trabalho apresenta possíveis soluções para a oferta de formação de professores para a } \\
\text { construção de jogos educacionais digitas? }\end{array}$ \\
\hline CQ4 & O trabalho deixa claro suas limitações de pesquisa? \\
\hline CQ5 & $\begin{array}{l}\text { O trabalho discute possíveis dificuldades na oferta de formação destinada a professores } \\
\text { para a construção de jogos educacionais digitais? }\end{array}$ \\
\hline
\end{tabular}

Fonte: Dados da pesquisa (2021).

Como parâmetro para medir a "qualidade" dos estudos selecionados, foi definida uma escala de pesos, mostrada no Quadro 7, para medir se os trabalhos atendiam totalmente $(1,0)$, atendiam parcialmente $(0,5)$ ou não atendiam $(0,0)$ aos critérios de qualidade propostos e analisados.

Quadro 7 - Escala utilizada para avaliar os critérios de qualidade.

\begin{tabular}{|l|c|}
\hline \multicolumn{1}{|c|}{ Descrição } & Peso \\
\hline Atende totalmente & 1,0 \\
\hline Atende parcialmente & 0,5 \\
\hline Não atende & 0,0 \\
\hline
\end{tabular}

Fonte: Dados da pesquisa (2021).

Tanto os critérios de qualidade, quanto a escala utilizada para medi-los foram essenciais para a realização da avaliação de qualidade, que serviu para determinar a relevância dos estudos finais escolhidos e que terão seus resultados apresentados na Seção 3 deste artigo.

Por fim, mediante todos os passos seguidos e expostos por meio desta seção, apresentamos na Seção 3 os resultados encontrados a partir da condução desta RSL. 


\section{Resultados}

A busca e a análise dos estudos primários encontrados ocorreram no período de maio a junho de 2021. Por meio da String de busca formulada (Quadro 1), foram encontrados 183 estudos em cinco diferentes bases de busca, e após a aplicação dos critérios de inclusão e exclusão (Quadros 3 e 4) e também da análise dos trabalhos seguindo as etapas listadas no Quadro 5 , foram selecionados ao final, quatro estudos primários, que apresentam uma discussão teórica ou experiência prática envolvendo a oferta de formação destinada a professores para a construção de JED.

O quantitativo de estudos selecionados seguindo as etapas especificadas no Quadro 5, pode ser observado de forma detalhada por etapa, por meio do Quadro 8.

Quadro 8 - Quantitativo de estudos selecionados por etapas.

\begin{tabular}{|l|c|c|c|c|c|c|c|}
\hline \multicolumn{2}{|c|}{} & \multicolumn{2}{c|}{ ETAPA 1 } & \multicolumn{2}{c|}{ ETAPA 2 } & \multicolumn{2}{c|}{ ETAPA 3 } \\
\hline $\begin{array}{c}\text { Bases de } \\
\text { Busca }\end{array}$ & $\begin{array}{c}\text { Trabalhos } \\
\text { Encontrados }\end{array}$ & Excluídos & Incluídos & Excluídos & Incluídos & Excluídos & Incluídos \\
\hline $\begin{array}{l}\text { ACM Digital } \\
\text { Library }\end{array}$ & 14 & 14 & 0 & 0 & 0 & 0 & 0 \\
\hline Google Scholar & 100 & 90 & 10 & 4 & 6 & 2 & 4 \\
\hline $\begin{array}{l}\text { Portal de } \\
\text { Periódicos } \\
\text { CAPES }\end{array}$ & 40 & 37 & 3 & 2 & 1 & 1 & 0 \\
\hline REDIB & 17 & 16 & 1 & 1 & 0 & 0 & 0 \\
\hline Scopus & 12 & 12 & 0 & 0 & 0 & 0 & 0 \\
\hline \multicolumn{1}{|c|}{ TOTAL } & $\mathbf{1 8 3}$ & $\mathbf{1 6 9}$ & $\mathbf{1 4}$ & $\mathbf{7}$ & $\mathbf{7}$ & $\mathbf{3}$ & $\mathbf{4}$ \\
\hline
\end{tabular}

Fonte: Dados da pesquisa (2021).

Considerando a escala de pesos mostrados no Quadro 7 e, também, a quantidade de critérios de qualidade definidos, o valor mínimo que um trabalho poderia alcançar após a realização da avaliação de qualidade, corresponde a 0,00. Já o valor máximo que um trabalho poderia alcançar corresponde ao valor de 5,00.

Desta forma, a partir da realização da avaliação de qualidade foi possível constatar que o valor médio geral de avaliação dos trabalhos analisados, corresponde ao quantitativo de 2,25, conforme mostrado no Quadro 9.

Quadro 9 - Resultado da avaliação de qualidade.

\begin{tabular}{|c|c|c|c|c|c|c|}
\hline ESTUDO & CQ1 & CQ2 & CQ3 & CQ4 & CQ5 & TOTAL \\
\hline E1 & 1,00 & 1,00 & 0,00 & 0,00 & 0,50 & 2,50 \\
\hline E2 & 1,00 & 1,00 & 0,00 & 0,00 & 0,00 & 2,00 \\
\hline E3 & 1,00 & 0,50 & 0,00 & 0,00 & 1,00 & 2,50 \\
\hline E4 & 1,00 & 0,50 & 0,00 & 0,00 & 0,50 & 2,00 \\
\hline VALOR MÉDIO & $\mathbf{1 , 0 0}$ & $\mathbf{0 , 7 5}$ & $\mathbf{0 , 0 0}$ & $\mathbf{0 , 0 0}$ & $\mathbf{0 , 5 0}$ & $\mathbf{2 , 2 5}$ \\
\hline
\end{tabular}

Fonte: Dados da pesquisa (2021).

Dos quatro estudos avaliados, dois obtiveram a pontuação de 2,00 cada. Enquanto os outros dois estudos, atingiram o mesmo quantitativo de pontos, ambos obtiveram o valor de 2,50 cada. 
A seguir, são detalhados os valores médios obtidos para cada critério de qualidade, resultantes da avaliação de qualidade realizada:

- Para o CQ1 o valor médio obtido foi de 1,00. Nesse sentido é possível apontar que os trabalhos encontrados relacionados à oferta de formação destinada a professores para a construção de JED, apresentam definições claras de seus objetivos de pesquisa;

- Para o CQ2 o valor médio obtido foi de 0,75. Dessa forma é possível determinar que grande parte dos trabalhos apresentam propostas de formações que se destinam ao público-alvo docente;

- Para o CQ3 o valor médio obtido foi de 0,00. Considerando isso é possível afirmar que os estudos encontrados não apontam possíveis soluções para a oferta de formação direcionada a professores para a construção de jogos educacionais digitas;

- Para o CQ4 o valor médio obtido foi de 0,00. Nessa ótica é possível inferir que os estudos analisados não deixam claro em seu texto suas limitações de pesquisa;

- Para o CQ5 o valor médio obtido foi de 0,50. Desse modo é possível apontar que uma parte dos estudos selecionados não apontam as possíveis dificuldades encontradas no que se refere à formação de professores para a construção de JED.

Por fim, destacamos que os dados e os resultados apresentados neste trabalho podem ser consultados também na planilha elaborada para auxiliar na condução da RSL. A planilha de condução da revisão pode ser acessada no link: https://bit.ly/planilha-conducao-rsl.

\section{Respostas às Questões de Pesquisa}

Nesta seção, buscamos trazer à luz respostas às questões de pesquisa definidas na etapa de planejamento desta revisão sistemática de literatura.

\subsection{Existe a oferta de formação destinada a professores para a construção de jogos educacionais digitais?}

A partir da análise dos trabalhos finais selecionados (E1, E2, E3 e E4), foi possível constatar algumas experiências de formação pontuais em um quantitativo relativamente pequeno, porém relevante, sendo que algumas que dessas formações foram realizadas com enfoque em públicos específicos de programa governamentais (E1).

Dessa forma, é possível determinar que existem, ainda que pontuais e para públicos específicos, de propostas de formação destinadas tanto a professores ainda em formação (E3 e E4) como para professores que já atuam no âmbito da sala de aula (E1, E2 e E3).

\subsection{Qual o perfil de quem ministra/oferta formação a professores para a construção de jogos educacionais digitais?}

Ainda de acordo com o resultado da análise dos trabalhos foi possível identificar que comumente o perfil de quem ministra/oferta esse tipo de formação, está relacionado a estudantes e professores de instituições de ensino superior públicas ligados a programas de pós-graduação em nível de mestrado e doutorado (E1, E2, E3, E4), assim como professores e outros servidores ligados a secretarias de educação de redes municipais de ensino (E4).

\subsection{Como é realizada a oferta de formação destinada a professores para a construção de jogos educacionais digitais?}

Dentre os estudos analisados, foi possível observar que as propostas de formação ocorreram em diferentes formatos, como curso online (E3), oficinas presenciais (E1, E2) e curso de extensão presencial (E4). 


\subsection{Que desafios podem ocorrer na oferta de formação destinada a professores para a construção de jogos educacionais digitais?}

Os principais desafios relatados nos estudos analisados dizem respeito à falta de conhecimento dos participantes em relação a algumas tecnologias digitais de informação e comunicação (TDIC) e ainda em relação a conhecimentos básicos de linguagem de programação e sobre ambientes de desenvolvimento dos jogos, como Scratch e Construct, por exemplo.

Todavia, foi possível perceber, por meio do relato dos autores dos trabalhos analisados, que, a partir das experiências de formação os professores se sentiram motivados e empenhados ao longo do processo e conseguiram produzir ao final das experiências, jogos educacionais digitais relevantes e funcionais que possuem potencial para serem aplicados em sala de aula.

\section{Resumos e Comparação entre os Trabalhos Encontrados}

Nesta seção, apresentaremos alguns breves resumos sobre as experiências de formação encontradas nos estudos finais selecionados a partir da RSL. Além disso, apresentaremos ainda uma comparação realizada entre todos trabalhos analisados.

\subsection{A construção de jogos digitais na escola: um relato de experiência na formação de professores}

O trabalho de Araujo, Silva e Aranha (2016), traz à luz uma experiência de formação realizada em escolas públicas de tempo integral de redes municipais e estadual de diferentes municípios do Rio Grande do Norte (RN). A ação de formação que trabalhou concepções e processos básicos relacionados ao Game Design, foi realizada com 229 professores da educação básica que atuavam à época em escolas que desenvolviam ações do programa "Mais Educação" do Ministério da Educação.

Os autores revelam a partir do estudo, que a experiência de formação por eles executada ocorreu por meio de 09 oficinas presenciais, possuindo 04 horas de duração cada, totalizando assim a carga horária total de 36 horas de formação ofertadas a professores de escolas públicas da educação básica do estado do RN.

Ainda de acordo com os autores, foram trabalhados com os docentes participantes, conceitos fundamentais ligados à área de Game Design, no qual foram exploradas as principais concepções ligadas aos jogos digitais, assim como os principais passos a serem seguidos e executados na construção destes.

No que se refere à metodologia utilizada por Araujo et al. (2016) para o desenvolvimento da ação de formação, estes apontam que foram seguidos os procedimentos de levantamento bibliográfico para busca e coleta de materiais e referências que embasassem a experiência formativa; planejamento e preparação de materiais para a execução das oficinas; desenvolvimento das oficinas com os professores; realização de seminário para apresentar aos docentes cursistas os resultados alcançados a partir da formação executada e aplicação junto aos participantes de um questionário visando à análise e avaliação das oficinas ofertadas.

Ao longo da execução das oficinas, os autores propuseram e construíram junto com os docentes participantes um documento de design de jogo ou Game Design Document (GDD), que se trata de documento guia, geralmente em forma de texto e bem ilustrado, que é criado por um designer de jogos a fim de descrever inúmeros elementos que podem vir a fazer parte de um jogo, como as mecânicas utilizadas, a narrativa a ser seguida, a meta da ser alcançada e também os elementos estéticos que podem fazer parte do jogo, além de outras informações que ajudarão na comunicação entre profissionais envolvidos no processo de desenvolvimento de um jogo e no entendimento do que se pretende construir (Motta \& Junior, 2013).

Para a construção do GDD, os autores da ação de formação definiram um problema central que consistia em: “criar um jogo para adolescentes, que trabalhasse habilidades em componentes curriculares do Ensino Básico, como Português, Matemática, História, Geografia, entre outros” (Araujo et al., 2016). A partir deste problema, os participantes envolvidos deveriam propor possíveis soluções por meio do GDD ao qual haviam sido incumbidos de criar. 
Como resultado, os autores apontam que foram propostas duas soluções pelos professores participantes da formação, uma da área de Língua portuguesa e outra que compreende as áreas de Geografia e Matemática.

Diante disso, Araujo et al. (2016) consideram que os professores participantes conseguiram compreender o objetivo da formação realizada, que ocorreu por meio de oficinas, o que pode, segundo os autores, sinalizar uma possível viabilidade na aplicação de processos de construção de jogos digitais nas escolas por meio deste modelo de formação.

Por fim, os autores apontam que a ação formativa possibilitou aos professores o conhecimento sobre noções básicas referentes aos jogos educacionais digitais, bem como sobre o processo de construção desses jogos. Além disso, os autores apontam que a experiência trouxe aos participantes, uma contribuição importante a respeito de como os docentes podem intervir na sala de aula com os estudantes, por meio da aplicação de estratégias inovadoras capazes de estimular o aprendizado destes (Araujo et al., 2016).

\subsection{Estudo Piloto para a Formação de Professores na Construção de Jogos Digitais Utilizando o Ambiente Scratch}

No trabalho de Greis, Freitas, Danielli e Cardoso (2020), é apresentada uma experiência de formação em formato de oficina, realizada no ano de 2016 para 30 professores da rede municipal de ensino do município de Florianópolis no estado de Santa Catarina (SC). No qual, de acordo com o relato dos autores de um total de 30 docentes participantes, apenas 15 frequentaram sem falta a todos os encontros de formação propostos.

Nesse sentido, ainda de acordo com o relato dos autores do trabalho analisado, a experiência de formação se deu por meio de 03 encontros presenciais, com duração de 08 horas por cada encontro realizado, o que totalizou uma carga horária final de 24 horas de formação.

Um fato interessante relatado pelos autores do estudo é o de que todos os docentes participantes da formação ofertada atuavam especificamente em salas de informática de suas respectivas escolas.

Ainda em relação à ação de formação desenvolvida por Greis et al. (2020), esta teve, como principal objetivo, a construção de jogos digitais utilizando o ambiente de desenvolvimento online conhecido como Scratch, que utiliza uma linguagem de programação por blocos, que pode se mostrar útil para se trabalhar com públicos que possuem pouco ou nenhum conhecimento sobre programação de computadores.

Sobre a opção pelo uso do ambiente online de programação Scratch, os autores justificaram a escolha da ferramenta pela facilidade de cadastro e uso desta por parte dos professores, sem a necessidade de instalar qualquer software para a utilização.

Em relação à metodologia utilizada para o desenvolvimento da experiência de formação, Greis et al. (2020) afirmam que foram realizadas diversas ações ao longo do três encontros realizados, de forma que no primeiro encontro foram seguidos os seguintes passos: aplicação de um questionário inicial para coleta de dados a respeito do perfil dos participantes; exposição inicial do objetivo da formação; realização de uma dinâmica com os participantes; realização de um debate a respeito da dinâmica; aplicação de exercícios de lógica de programação e realização de uma atividade offline que consistiu no desenvolvimento um game design document.

Já no segundo encontro, os autores apontam que foram realizadas as seguintes ações: uma discussão a respeito dos GDD criados e apresentados no primeiro encontro; a divulgação de um ambiente colaborativo (comunidade de aprendizagem) e a divulgação de um site para apoiar e realização das aulas expositivas a respeito do Scratch.

Por fim, no terceiro encontro de formação realizado, foram abordados com os professores cursistas os seguintes pontos: a realização de uma aula expositiva para apresentar os recursos de desenvolvimento avançados presentes no Scratch e a realização de uma exposição dos produtos criados pelos cursistas, além da realização de um último debate entre os participantes a respeito da oficina. 
Como resultado da experiência de formação, Greis et al. (2020) afirmam que foram produzidos ao todo 03 jogos educacionais digitais por meio da linguagem de programação Scratch, no qual, dois dos três jogos construídos (Jogo da Reciclagem e Jogo de Letramento) foram desenvolvidos pelos próprios professores cursistas sem qualquer auxílio e um último jogo (Letramento com Webcam) foi construído contando com o auxílio direto dos instrutores da formação.

Ademais, os autores destacam alguns fatos interessantes percebidos por eles ao longo de toda a formação ofertada, tais como o fato de que a maioria dos professores participantes gostarem bastante de jogar games de diferentes gêneros como jogos mobile e jogos casuais em diferentes plataformas como consoles, smartphones e computador.

Outro ponto interessante destacado por Greis et al. (2020), é em relação ao domínio da alguma linguagem de programação por parte dos docentes, onde, foi possível constatar que grande parte dos professores não dominavam essa técnica, apesar de afirmarem já terem sentido a necessidade de criar jogos e outras mídias para fins educativos, porém não sabiam como fazê-las.

Em conclusão, os autores apontam que de forma inicial o que se pôde perceber era o fato de que os docentes participantes da formação ao fazerem uso de jogos na educação restringiam-se a utilizar jogos comerciais específicos, que não haviam sido criados para finalidades educativas.

No entanto, a partir da experiência de formação realizada tornou-se possível evidenciar uma mudança em relação a isso, uma vez que os professores ao participarem ativamente na construção de jogos educacionais digitais puderam se expressar e construir seus próprios recursos pedagógicos digitais, o que contribui inclusive para que os docentes pudessem enxergar o potencial da utilização de recursos tecnológicos digitais em seu fazer pedagógico.

\subsection{Formação online para o desenvolvimento do Pensamento Computacional em professores de Matemática}

O estudo de Barcelos, Bortoletto e Andrioli (2016), apresenta uma ação de formação destinada a professores de matemática, visando ao desenvolvimento de competências relacionadas ao pensamento computacional (PC), por meio da construção de jogos digitais.

Os autores justificaram que a escolha por se trabalhar o PC por meio da construção de jogos digitais, se deu em virtude deste ser, de acordo com eles, um aspecto capaz de motivar os professores a participarem da formação, em virtude da notável presença dos jogos digitais na vida de muitas crianças e adolescentes da educação básica, assim como na vida de estudantes de nível superior do país e até mesmo em cursos de formação de professores.

Com relação à experiência de formação realizada, Barcelos et al. (2016) apontam que a mesma ocorreu por meio de um curso de extensão ofertado em parceria com a coordenadoria de extensão do Instituto Federal de Educação, Ciência e Tecnologia de São Paulo (IFSP), campus Guarulhos.

Ainda de acordo com os autores, foram abertas 20 inscrições para o curso, onde 10 dessas 20 inscrições foram destinadas com prioridade para professores da área de matemática que atuavam em escolas da educação básica da rede pública de ensino. No entanto, os autores deixam claro que as vagas prioritárias poderiam ser preenchidas caso não houvesse interesse do público ao qual foram destinadas e que podiam se inscrever também estudantes ainda em formação, que estivessem matriculados em cursos superiores em nível de licenciatura.

Dessa forma, ao final da seleção realizada, que se deu por meio de sorteio, foram contemplados um total de 05 professores de matemática que já atuavam na educação básica, 14 estudantes de licenciatura das áreas de matemática e/ou pedagogia e 01 aluno matriculado em um curso superior da área de informática.

A experiência de formação ofertada por Barcelos et al. (2016), ocorreu no formato online por meio do Ambiente Virtual de Ensino e Aprendizagem (AVEA) Moodle. O curso foi organizado em 10 módulos dentro do AVEA, no qual foi ofertado um módulo a cada semana, em um período total de 10 semanas de curso. 
Em relação aos conteúdos trabalhados no decorrer da experiência formativa, os autores do trabalho apontam que nos cinco primeiros módulos, foram trabalhados com os cursistas conteúdos relacionados à programação de computadores e também conceitos iniciais relacionados à construção de jogos digitais. Já os últimos cinco módulos da formação tiveram como objetivo o aprofundamento e reflexão dos participantes a respeito das atividades propostas e a construção do projeto final do curso (que consistia na produção de jogos educacionais digitais).

Como suporte ao desenvolvimento das atividades de programação e também na construção dos jogos digitais produzidos pelos participantes ao final do curso, foi utilizado o ambiente de programação Scratch.

Como resultado da formação, os autores afirmam que foram produzidos vários jogos digitais com finalidades educacionais de diferentes gêneros como jogos de ação, puzzle e até mesmo quizz, o que, de acordo com os autores, ajudou a consolidar os conhecimentos trabalhados com os participantes ao longo do curso de formação ofertado.

Um ponto importante ressaltado por Barcelos et al. (2016), é que a grande maioria dos cursistas que finalizaram o projeto final de construção dos jogos, não possuíam experiências anteriores com programação de computadores e desenvolvimento de jogos.

Por fim, os autores elucidam ainda que mesmo o curso tendo possuído como principal foco o desenvolvimento de competências e habilidades relacionadas ao PC, a partir da análise dos dados por eles coletados, foi possível notar um maior engajamento por parte dos professores nas atividades que envolviam diretamente a construção de jogos digitais, o que, segundo eles, pode indicar um forte potencial na temática escolhida para formações de professores.

\subsection{Jogos digitais, ludicidade e ensino de ciências: a experiência formativa do Educgame}

No trabalho de Caixeta et al. (2019), é apresentada uma experiência de formação que foi realizada por meio de um curso de extensão presencial intitulado EducGame e ofertado pelos autores em parceria com o Laboratório de Apoio e Pesquisa em Ensino de Ciências da Faculdade Planaltina vinculada à Universidade de Brasília e com a participação voluntária de um professor vinculado ao Centro de Ensino Unificado do Distrito Federal.

Caixeta et al. (2019), deixam claro que o objetivo do curso foi fomentar um espaço de formação inicial visando ao desenvolvimento de jogos digitais por futuros(as) docentes.

Os autores apontam ainda, que o curso foi realizado de forma gratuita para 10 estudantes de cursos de graduação em nível de licenciatura da área de Ciências Naturais.

A execução do curso se deu por meio de 10 encontros, realizados durante 10 dias com duração de 03 horas a cada encontro, o que totalizou uma carga horária de 30 horas de duração.

Ainda em relação à ação de formação, os autores afirmam que dos 10 encontros totais realizados, 06 foram destinados para ministrar aulas teóricas e 04 para a realização de aulas práticas relacionadas aos jogos digitais, utilizando como suporte para o desenvolvimento das atividades e construção dos jogos a plataforma Construct, em sua versão clássica.

Outro ponto destacado pelos autores em relação à formação, é que dos 10 cursistas participantes, apenas 06 concluíram por completo o curso ofertado.

Como resultado da realização da ação de formação, Caixeta et al. (2019) afirmam que foram desenvolvidos ao final um total de 03 jogos digitais com finalidades educacionais (PROERD Game, Nhac Game e Herói Ambiental).

Ainda em relação aos jogos digitais construídos, os autores destacaram que foi gratificante notar o prazer e a alegria dos cursistas ao verem seus produtos finais prontos e funcionais.

A respeito dos desafios enfrentados em relação à formação, os autores destacaram como um dos principais desafios, o fato de a ferramenta de desenvolvimento Construct possuir algumas limitações em sua versão clássica, que é gratuita. 
Já em relação às conquistas alcançadas por meio da formação, os autores apontaram que uma das principais conquistas se deu ao fato de os cursistas poderem estudar sobre os recursos digitais apresentados e como eles podem contribuir para a construção de jogos digitais.

Por fim, Caixeta, et al. (2019) apontam que a experiência de formação realizada por meio do curso de extensão ofertado por eles, evidenciou que é totalmente possível construir jogos digitais como ferramentas pedagógicas ainda durante o processo de formação inicial de professores.

\subsection{Comparação entre os trabalhos}

Mediante a análise dos trabalhos finais selecionados a partir da RSL, torna-se possível realizar uma comparação entre diversas características em comum encontradas nos estudos.

Dentre as principais características encontradas e apresentadas no Quadro 10, estão: o tipo de formação realizada em cada experiência de formação; o modelo de formação adotado; o público-alvo atendido em cada experiência formativa; a quantidade de pessoas atendidas em cada formação realizada; a abrangência e a carga-horária total de cada ação de formação.

Quadro 10 - Comparação entre os trabalhos finais selecionados na RSL.

\begin{tabular}{|c|c|c|c|c|}
\hline Autores & Araujo et al. (2016) & $\begin{array}{l}\text { Greis, et al. } \\
(2020)\end{array}$ & Barcelos et al. (2016) & Caixeta, et al. (2019) \\
\hline Trabalho & $\begin{array}{l}\text { A construção de } \\
\text { jogos digitais na } \\
\text { escola: um relato de } \\
\text { experiência na } \\
\text { formação de } \\
\text { professores }\end{array}$ & $\begin{array}{l}\text { Estudo piloto para a } \\
\text { formação de professores } \\
\text { na construção de jogos } \\
\text { digitais utilizando o } \\
\text { ambiente } \text { Scratch }\end{array}$ & $\begin{array}{l}\text { Formação online para } \\
\text { o desenvolvimento do } \\
\text { Pensamento } \\
\text { Computacional em } \\
\text { professores de } \\
\text { Matemática }\end{array}$ & $\begin{array}{l}\text { Jogos digitais, } \\
\text { ludicidade e ensino } \\
\text { de ciências: a } \\
\text { experiência } \\
\text { formativa do } \\
\text { EducGame }\end{array}$ \\
\hline $\begin{array}{l}\text { Tipo de } \\
\text { formação }\end{array}$ & Oficina & Oficina & Curso de extensão & Curso de extensão \\
\hline $\begin{array}{l}\text { Modelo de } \\
\text { formação }\end{array}$ & Presencial & Presencial & Online & Presencial \\
\hline Público-alvo & $\begin{array}{l}\text { - Professores da } \\
\text { educação básica } \\
\text { (rede pública). }\end{array}$ & $\begin{array}{l}\text { - Professores da } \\
\text { educação básica. }\end{array}$ & $\begin{array}{l}\text { - Professores de } \\
\text { matemática da } \\
\text { educação básica (rede } \\
\text { pública); } \\
\text { - Estudantes de } \\
\text { licenciatura } \\
\text { (matemática, } \\
\text { pedagogia e } \\
\text { informática). }\end{array}$ & $\begin{array}{l}\text { - Estudantes de } \\
\text { licenciatura (ciências } \\
\text { naturais). }\end{array}$ \\
\hline $\begin{array}{l}\text { Quantidade } \\
\text { de pessoas } \\
\text { atendidas }\end{array}$ & 229 pessoas & 30 pessoas & 20 pessoas & 10 pessoas \\
\hline $\begin{array}{l}\text { Abrangência } \\
\text { da formação }\end{array}$ & $\begin{array}{l}\text { Regional (atendeu } \\
\text { docentes de diversos } \\
\text { municípios do estado } \\
\text { do RN). }\end{array}$ & $\begin{array}{l}\text { Local (atendeu apenas } \\
\text { professores da rede } \\
\text { municipal de } \\
\text { Florianópolis/SC). }\end{array}$ & $\begin{array}{l}\text { Local (atendeu apenas } \\
\text { docentes e estudantes } \\
\text { de licenciatura de } \\
\text { Guarulhos/SP). }\end{array}$ & $\begin{array}{l}\text { Local (atendeu } \\
\text { apenas estudantes de } \\
\text { licenciatura de } \\
\text { Brasília/DF) }\end{array}$ \\
\hline $\begin{array}{l}\text { Carga- } \\
\text { horária total }\end{array}$ & 36 horas & 24 horas & Não informada & 30 horas \\
\hline
\end{tabular}

Fonte: Dados da pesquisa (2021).

Em relação ao tipo de formação, é possível notar que entre todos os trabalhos analisados foram utilizados apenas dois tipos de formação (oficina e curso de extensão), o que pode sinalizar uma tendência em relação à utilização desses tipos no que se refere à capacitação de professores. Outro ponto a se ressaltar é quanto à eficácia dos tipos de formação, uma vez que todas as experiências realizadas e reportadas nos estudos alcançaram resultados positivos e relevantes. 
Já com relação ao modelo de formação utilizado, nota-se uma superioridade na realização de ações no formato presencial em relação ao formato online, uma vez que apenas a experiência realizada por Barcelos et al. (2016) aconteceu de forma online por meio de um AVEA.

Com relação ao público-alvo atendido, podemos notar que a maioria das formações realizadas oportunizou aos professores o aprendizado de novos conceitos, técnicas e ferramentas relacionadas à construção de jogos digitais que podem ser trabalhados junto aos estudantes.

Outro ponto a se destacar é que grande parte das formações ocorreram como uma espécie de formação continuada para os professores, onde apenas a experiência de formação de Caixeta, et al. (2019), não atendeu à professores que já atuavam na educação básica, se limitando a atender apenas docentes em formação. No entanto, isso não se torna um problema, uma vez que é de extrema importância que professores tenham contato com experiências enriquecedoras como estas, ainda durante o processo de formação inicial (Libâneo, 2004).

No que se refere à quantidade de pessoas atendidas, podemos observar que na maioria das experiências se trata de uma quantidade relativamente pequena, sendo a ação que mais atendeu pessoas a realizada por Araujo et al. (2016), mesmo esta tendo acontecido de maneira presencial. Enquanto a formação realizada por Barcelos et al. (2016) que ocorreu de forma online e teria a capacidade de atender a um público maior em função da não existência de limitação espacial ou geográfica, atendeu a um público bem menor.

Contudo, em relação à carga-horária total de formação, se desconsiderarmos a experiência de Barcelos et al. (2016) que não informou a carga-horária da ação realizada, chegamos a uma média de 30 horas de formação.

\section{Ameaças à Validade do Trabalho}

Assim como qualquer trabalho científico, este estudo possui limitações e não está isento de eventuais ameaças à validade do mesmo. Dessa forma, uma das principais ameaças à validade deste está relacionada à construção da String de busca, uma vez que, a que foi construída e utilizada neste trabalho pode acabar não retornando todos os estudos relevantes ligados à temática investigada nas bases utilizadas, mesmo tendo sido realizados testes com a mesma.

Outra ameaça está relacionada ao fato de terem sido utilizadas bases de dados que não permitem o acesso público a alguns trabalhos nelas indexados. Isso não compromete de nenhuma forma a qualidade dos estudos encontrados e analisados, porém pode ter reduzido o número de trabalhos encontrados durante o processo de busca.

Por fim, ressaltamos que suscetíveis falhas humanas podem vir a ocorrer durante o processo de análise dos estudos encontrados. Todavia, acreditamos que o rigor científico aplicado ao trabalho por seus autores, é suficiente para garantir a validação do mesmo.

\section{Considerações Finais}

A partir deste estudo é possível observar a existência de algumas inciativas de formação destinada a professores para a construção de jogos digitais com finalidade educacional. Todavia, pode-se notar que ainda há muito espaço e necessidade de mais ações formativas continuadas destinadas a docentes, principalmente os que atuam no segmento da Educação Básica, visto que as competências e habilidades adquiridas por estes nessas formações, podem auxiliar o trabalho docente, contribuindo para o enriquecimento das práticas pedagógicas destes profissionais.

Torna-se possível notar ainda, que grande parte das iniciativas destinadas a formar professores para a o design e construção de jogos educacionais digitais, são ofertadas por docentes e discentes de programas de pós-graduação nacionais e também por profissionais que atuam diretamente na área da educação, o que pode indicar a pouca ação governamental por 
meio de políticas públicas de formação de professores a fim de capacitar profissionais da educação para a construção ou participação na construção de recursos educativos digitais.

Destaca-se ainda, que as experiências de formação encontradas foram planejadas e ofertadas em diferentes formatos para ser aplicadas junto ao público docente e que as dificuldades mais evidentes com relação à oferta dessas formações, estão relacionadas com o pouco ou nenhum conhecimento dos profissionais com relação às TDIC, ao campo dos jogos digitais ou a alguma linguagem de programação que pode ser utilizada para o desenvolvimento destes.

Por fim, ressaltamos que existe a necessidade da realização de novos estudos capazes de trazer à luz dados, informações, reflexões e respostas que acabaram não sendo compreendidas por meio deste artigo e que se referem à oferta de formação para o design e construção de JED para e com a participação de educadores.

\section{Agradecimentos}

Agradecemos ao Programa de Pós-graduação em Inovação em Tecnologias Educacionais, ao Instituto Metrópole Digital e à Universidade Federal do Rio Grande do Norte, pelo apoio financeiro concedido para a publicação deste artigo científico.

Agradecemos também a Ednny Kelly de Almeida Sales e a Maria Clara Medeiros Silva, mestrandas do PPgITE, que contribuíram conosco realizando a tradução do nosso resumo para as línguas estrangeiras.

\section{Referências}

ACM Digital Library. (2021). Base de dados do ACM Digital Library. https://dl.acm.org/.

Amélio, C. (2018, outubro). A Indústria e o mercado de Jogos Digitais no Brasil. Anais do XVII Simpósio Brasileiro de Jogos e Entretenimento Digital (SBGames), Paraná, PR, Brasil, 17.

Araujo, G., Silva, R., \& Aranha, E. (2016, outubro). A construção de jogos digitais na escola: um relato de experiência na formação de professores. Anais do XXII Workshop de Informática na Escola, Uberlândia, MG, Brasil, 22.

Barcelos, T., Bortoletto, R., \& Andrioli, M. (2016, outubro). Formação online para o desenvolvimento do Pensamento Computacional em professores de Matemática. Anais dos Workshops do V Congresso Brasileiro de Informática na Educação, Minas Gerais, MG, Brasil, 5.

Boller, S., Kapp, K. (2018). Jogar para Aprender: tudo o que você precisa saber sobre o design de jogos de aprendizagem eficazes. DVS Editora.

Brasil (1994). Ministério da Educação. Programa nacional de informática educativa. MEC. http://www.dominiopublico.gov .br/download/texto/me002415.pdf.

Brasil (2007). Decreto $n^{o}$ 6.300, de 12 de dezembro de 2007. Dispõe sobre o Programa Nacional de Tecnologia Educacional - ProInfo. DOU. http://www.planalto.gov.br/ccivil_03/_ato2007-2010/2007/decreto/d6300.htm.

Brasil. (2018). II Censo da Indústria Brasileira de Jogos Digitais aponta crescimento de games no Brasil. http://cultura.gov.br/2o-censo-da-industriabrasileira-de-jogos-digitais-aponta-crescimento-de-games-no-brasil-2/.

Brasil (2021). Lei $n^{o}$ 14.180, de 01 de julho de 2021. Institui a Política de Inovação Educação Conectada. DOU. https://legis.senado.leg.br/norma/34251506/publicacao/34254618.

Caixeta, J., Cader-Nascimento, F., dos Anjos, L., Silva, T., Leite, L., Guimarães, C., \& Soares, M. (2019). Jogos digitais, ludicidade e ensino de ciências: a experiência formativa do Educgame. Ciências em Foco, 12(1), 4-13.

Educause (2021). Horizon Reports. https://library.educause.edu/resources/2021/2/horizon-reports.

Google Scholar. (2021). Base de dados do Google Scholar. https://scholar.google.com/

Greis, L., de Freitas, K., Danielli, F., \& Cardoso, F. (2020). Estudo Piloto para a Formação de Professores na Construção de Jogos Digitais Utilizando o Ambiente Scratch. Revista EducaOnline, 14(1), 1-15.

Kenski, V. M. (2013). Tecnologias e tempo docente. Papirus Editora.

Kitchenham, B., Charters, S. (2007). Guidelines for performing systematic literature reviews in software engineering. Information and Software Technology https://www.elsevier.com/_data/promis_misc/525444systematicreviewsguide.pdf.

Libâneo, J. (2004). Organização e gestão da escola: teoria e prática (5a ed.). Alternativa.

Mattar, J. (2010). Games em educação: como os nativos digitais aprendem. Pearson Prentice Hall. 
Research, Society and Development, v. 10, n. 13, e519101321585, 2021

(CC BY 4.0) | ISSN 2525-3409 | DOI: http://dx.doi.org/10.33448/rsd-v10i13.21585

McGonigal, J. (2012). A realidade em jogo: Por que os games nos tornam melhor e como eles podem mudar o mundo. Editora Best Seller.

Meira, L., \& Blikstein, P. (Orgs.). (2020). Ludicidade, jogos digitais e gamificação na aprendizagem. Penso Editora.

Motta, R., \& Junior, J. (2013). Short game design document (SGDD). Anais do XII Simpósio Brasileiro de Jogos e Entretenimento Digital (SBGames), 12, $115-121$.

Petry, A. S. (2016). Jogos digitais e aprendizagem: algumas evidências de pesquisas. In Alves, L., \& de Jesus Coutinho, I. (Orgs.). Jogos digitais $e$ aprendizagem: fundamentos para uma prática baseada em evidências, (pp. 43-60). Salvador, BA: Papirus Editora.

Portal de periódicos CAPES. (2021). Base de dados do Portal de periódicos CAPES. https://www-periodicos-capes-govbr.ezl.periodicos.capes.gov.br/index.php.

Prensky, M. (2001). Digital Natives, Digital Immigrants part 1. On the horizon. https://www.marcprensky.com/writing/Prensky\%20\%20Digital\%20Natives,\%20Digital\%20Immigrants\%20-\%20Part1.pdf.

Prensky, M. (2010). Não me atrapalhe, mãe - Eu estou aprendendo!: Como os videogames estão preparando nossos filhos para o sucesso no século XXI - $e$ como você pode ajudar!. São Paulo, SP: Phorte.

Prensky, M. (2012). Aprendizagem baseada em jogos digitais. Editora Senac.

Red Iberoamericana de Innovación y Conocimiento Científico. (2021). Base de dados da REDIB. https://www.redib.org/.

Scopus. (2021). Base de dados do Scopus. https://www.scopus.com/home.uri.

Tavares, L. M. (2021). Serious games. Intersaberes. 